\title{
Pesquisa e produção de conhecimento sobre a América Latina na ciência política brasileira
}

Research and production of knowledge about Latin America in the Brazilian political science

O Brasil tem passado por uma expansão acadêmica. A ampliação do número de programas de pós-graduação e a elevação na titulação do corpo docente das instituições de ensino superior têm levado a um crescimento na quantidade de grupos de pesquisa e no volume da produção científica.

As ciências sociais, em particular a ciência política, não fogem a essa regra. O Brasil conta com 192 núcleos de pesquisa cadastrados no Diretório de Grupos de Pesquisa do Conselho Nacional de Desenvolvimento Científico e Tecnológico ( $\mathrm{CNPq}$ ) na área de ciência política e relações internacionais (CNPq, 2014), 36 programas de pós-graduação em ciência política, sendo dezenove com mestrado e dezessete com mestrado e doutorado (Capes, 2014), e 133 periódicos que publicam sobre temas relacionados com ciência política (Qualis Capes, 2014).

A agenda de pesquisa da disciplina é diversa e inclui temas como eleições, comportamento político, instituições políticas, qualidade da democracia, transições de regime, políticas públicas e participação. A ciência política brasileira tem trabalhado com esses temas em referência ao próprio país ou às suas subunidades. Os estudos com uma abrangência regional ainda parecem ser pouco frequentes. A avaliação de que há um conhecimento incipiente sobre a América Latina no Brasil é recorrente (Lapa, 1977; Prado,

É mestre em ciência política pela Universidade Federal de Goiás (UFG).E-mail: tavaresgyn@gmail.com.

** É professor adjunto da área de ciência política da Universidade Federal de Goiás (UFG). E-mail: joaocarlosbotelho@hotmail.com. 
2001; Reichel, 2001; Soares, 2004), sobretudo quando comparado ao interesse dos Estados Unidos e da Europa pela região.

Prado (2001) resume bem essa perspectiva:

Muito já se tem escrito sobre a questão do distanciamento entre o Brasil e os demais países da América Latina. Afirma-se a admiração dos brasileiros pela cultura da Europa (e mais recentemente pela dos EUA), em contrapartida a uma postura de desconhecimento ou até mesmo de desprezo com relação à outra América, a de colonização espanhola. Tal visão traz desdobramentos de diversas ordens e repercute na esfera da educação (Prado, 2001, p. 10).

Com enfoque na pesquisa histórica, Reichel (2001) faz avaliação semelhante:

Era comum, assim, que, nos cursos de graduação, principalmente nos de universidades mais distantes dos principais centros culturais do país ou nos de recente criação, a temática latino-americana fosse ensinada através de uma bibliografia defasada, escassa e limitada. A pesquisa, por sua vez, também era restrita não apenas pela falta de acesso à documentação, mas pela própria dificuldade de se poder avaliar o estado geral da arte e, dessa maneira, problematizar temáticas relativas à América (Reichel, 2001, p. 7).

No caso da ciência política, Soares (2004) avalia que, há trinta anos, um curso de política latino-americana "não poderia ser dado no Brasil porque quase toda a bibliografia não estava disponível em nenhuma instituição brasileira. Nos anos 1990, a situação era semelhante: [...] havia pouquíssimos livros sobre a América Latina e pouquíssimos periódicos" (Soares, 2004, p. 10).

A influência dos Estados Unidos na pesquisa e na produção de conhecimento da ciência política brasileira também incide sobre a definição dos temas e da agenda da disciplina. Essa influência tem sua origem no início do processo de institucionalização da ciência política no Brasil, que foi marcado por "influxos internacionais estimulados pela Fundação Ford" (Keinert e Silva, 2010, p. 79), um importante ator ao longo do processo de desenvolvimento da disciplina no país.

Essa entidade filantrópica, fundada em 1936 nos Estados Unidos, teve um papel significativo, por exemplo, na injeção de recursos, já que, "através do financiamento de congressos, financiamento de pesquisas etc. a Fundação 
Ford foi a principal instituição impulsionadora da ciência política no Brasil" (Nascimento, 2008, p. 22).

De acordo com Keinert e Silva (2010, p. 79), com o processo de institucionalização da ciência política no Brasil e com o avanço da sociabilidade entre os grupos de acadêmicos a partir do núcleo mineiro/carioca, um "cânone disciplinar" passou a ser construído, articulando as novidades trazidas dos Estados Unidos com as referências ligadas aos ensaios de interpretação sobre a história política do Brasil.

Essas características do desenvolvimento da ciência política no país estariam relacionadas com um projeto abrangente dos Estados Unidos para exportar um modelo de "organização do trabalho intelectual" (Keinert e Silva, 2010, p. 82). Segundo os autores, esse projeto se inseria, no caso da América Latina, em um esforço de influência dos Estados Unidos sobre a região que se seguia ao agravamento das tensões do período da Guerra Fria, com a eclosão da Revolução Cubana em 1959. A atuação da Fundação Ford, então, seria um instrumento do esforço de influência e exportação do modelo de organização do trabalho intelectual.

Na América Latina, a atuação da entidade, segundo Keinert e Silva (2010), foi diferente da adotada, por exemplo, em África, Ásia e Oriente Médio, que recebiam assistência financeira estadunidense prioritariamente a órgãos governamentais. Já nos países latino-americanos, as primeiras missões da Fundação Ford teriam priorizado o financiamento a instituições acadêmicas, entre as quais estariam, no caso da ciência política brasileira, os departamentos da Universidade Federal de Minas Gerais (UFMG) e do Instituto Universitário de Pesquisas do Rio de Janeiro (Iuperj). Para os autores, a disciplina tinha um potencial a ser explorado pela fundação, como explicam:

Uma vez que as iniciativas de apoio da Fundação Ford apontavam para uma definição aplicada de conhecimento social, a ciência política viria a assumir uma posição estratégica em função de seu potencial em pautar a elaboração de políticas públicas. Trata-se da viabilização de um perfil disciplinar especializado que se ligaria a um gênero de pesquisas orientado pela proximidade à agenda política nacional e cujos esforços seriam canalizados para a análise das bases institucionais do regime liberal-democrático (Keinert e Silva, 2010, p. 82). 
Ao encontrar terreno fértil em Belo Horizonte e no Rio de Janeiro, a Fundação Ford teria instituído um sistema hierarquizado de bolsas de estudo para os respectivos corpos discentes, que "exigia dedicação integral, auxílio às atividades didáticas e apresentação de monografias ao final do ano" (Keinert e Silva, 2010, p. 84). Esse sistema teria gerado dois grupos de alunos, que se distinguiam exatamente pela forma como se envolviam com sua instituição e encaravam a carreira acadêmica.

Em uma análise dos enfoques da ciência política na América Latina a partir dos artigos publicados em revistas da área na Argentina, no Brasil e no México, Carpiuc (2014) observou algumas tendências a um predomínio do modo como se faz ciência política nos Estados Unidos. A autora verificou, por exemplo, uma orientação empírica e quantitativa na produção. Do total de textos avaliados, 56,8\% têm natureza empírica, sendo que, desse grupo, $54,3 \%$ utilizam alguma técnica quantitativa.

As próprias reflexões, como as que foram mencionadas, sobre o estado da ciência política no Brasil e na América Latina, parecem estar numericamente aquém do necessário. Segundo Nohlen (2006, p. 1), “existe poca autoreflexión sobre la disciplina y su desarrollo" na região.

Este trabalho busca oferecer contribuições nos dois sentidos, como um teste da hipótese de que a ciência política brasileira se interessa pouco pela América Latina e como uma reflexão sobre o estado da disciplina no país. A análise enfoca o campo de estudos sobre essa região na ciência política brasileira, ou seja, a pesquisa e a produção dos que atuam na disciplina no país sobre temas variados que tenham em comum a América Latina ou um, desde que não o Brasil, ou mais países da região como objeto de estudo. $\mathrm{O}$ Brasil, como país latino-americano, não está excluído do campo. A ressalva feita significa que um estudo de caso sobre o Brasil elaborado por um profissional da ciência política nacional não pode ser parte do que se produz no país sobre a América Latina, a não ser que se trabalhe com ao menos um segundo caso da região.

Um estudo para aferir o interesse da ciência política brasileira pela América Latina tem algumas justificativas. Em primeiro lugar, o Brasil tem priorizado na sua política externa as regiões onde se situa, a América Latina e, sobretudo, a América do Sul. Para um país que busca uma inserção regional maior, inclusive com a pretensão de liderança, é necessário aprofundar seu conhecimento sobre a América Latina. Isso não significa que a produção 
científica precisa se guiar por orientações de Estado ou de governo. A ideia é que para o Brasil ter uma inserção regional maior, o que se assume aqui como importante, é necessária a formação de um conhecimento mais aprofundado sobre a América Latina.

Além disso, o Brasil apresenta características culturais, históricas, políticas e socioeconômicas em comum com os demais países latino-americanos, o que faz com que a compreensão da região também ajude a conhecer melhor a realidade brasileira. No que se refere à própria disciplina, a ciência política brasileira precisa, se busca de fato uma internacionalização, expandir o número de casos que estuda, para aumentar a possibilidade de generalizar suas conclusões.

\section{Metodologia}

Para identificar os núcleos de pesquisa, a fonte foi o Diretório dos Grupos de Pesquisa no Brasil do CNPq. Como filtro, foram usadas as palavras-chaves "América Latina" e "latino-americana", a grande área Ciências Humanas e a subárea Ciência Política, a qual engloba ciência política e relações internacionais.

Um estudo semelhante foi realizado por Araújo (2009). Segundo ele:

[...] identificar os grupos de pesquisa pode auxiliar na caracterização, fortalecimento e consolidação (considerando o contexto institucional em que estão inseridos e as peculiaridades da área de conhecimento de cada um deles), na socialização e visibilidade dos grupos (produção científica: pesquisa e temáticas abordadas), entre outros (Araújo, 2009, p. 82).

Quanto à formação, foram avaliados os programas de pós-graduação strictu sensu em ciência política recomendados e reconhecidos pela Coordenação de Aperfeiçoamento de Pessoal de Nível Superior (Capes), que mantém um banco de dados com os cursos brasileiros de todas as áreas que seguem os padrões do Ministério da Educação. Esses programas foram analisados em relação a linhas de pesquisa, corpo docente, distribuição geográfica e institucional, data de criação e evolução. Também foram identificadas as vinculações dos cursos à área de América Latina.

Por fim, apresenta-se um levantamento da produção da ciência política brasileira sobre a América Latina. Para fazer isso, foram selecionados alguns 
dos principais periódicos brasileiros da área de avaliação de ciência política e relações internacionais e buscados artigos que se encaixam à definição adotada aqui para o campo de estudos da América Latina.

Soares, Souza e Moura (2011) analisam as publicações em oito revistas de ciência política e sociologia disponíveis no portal Scientific Eletronic Library Online (SciELO). Os periódicos considerados foram a Dados - Revista de Ciências Sociais, a Opinião Pública, a Revista Brasileira de Ciências Sociais, o Brazilian Political Science Review, a Lua Nova e a Revista de Sociologia e Política.

Neste trabalho, além dos seis periódicos já mencionados, foram consideradas a Revista Brasileira de Ciência Política, a Tempo Social e a Sociedade e Estado, para não se limitar aos estratos Qualis A1 e A2 na área de avaliação de ciência política e relações internacionais. A justificativa é que um levantamento que se concentrasse nos estratos A seria menos representativo da produção da ciência política brasileira sobre a América Latina. Os três periódicos incluídos são do estrato Qualis B1 e, como os demais, estão disponíveis no SciELO.

$\mathrm{O}$ ano em que se inicia a apresentação dos dados em cada caso é o primeiro ano para o qual os dados em questão estão disponíveis. Com isso, os períodos considerados são os mais abrangentes possíveis, evitando definições arbitrárias.

\section{A América Latina nos grupos de pesquisa cadastrados no CNPq}

Por meio do Diretório dos Grupos de Pesquisa do CNPq e de algumas palavras-chave relacionadas com a América Latina, foram identificados 45 núcleos de pesquisa da área de ciência política e relações internacionais cadastrados no órgão que trabalham com temas sobre a região. Esses grupos estão presentes em $63 \%$ dos estados, sendo os que têm mais núcleos o Rio Grande do Sul, com oito, o Paraná, com sete, e São Paulo e Rio de Janeiro, com seis grupos cada. Esses números fornecem a primeira indicação de que a pesquisa sobre a América Latina no Brasil se concentra no Sul e no Sudeste, em detrimento das demais regiões do país.

Ao analisar a distribuição dos núcleos pelas regiões brasileiras, observa-se, como mostra o Gráfico 1, que 38\% e 31\% deles estão, respectivamente, nas regiões Sul e Sudeste, ou seja, nelas estão concentrados quase $70 \%$ dos grupos que trabalham com temas relacionados com a América Latina. Essa distribuição é um reflexo da produção de conhecimento no Brasil, onde as principais universidades se concentram nos estados do Sul e do Sudeste, e da maior proximidade geográfica da região Sul com países que compõem o Cone Sul. 


\section{Gráfico 1 - Distribuição dos grupos de pesquisa pelas regiões bra- sileiras}

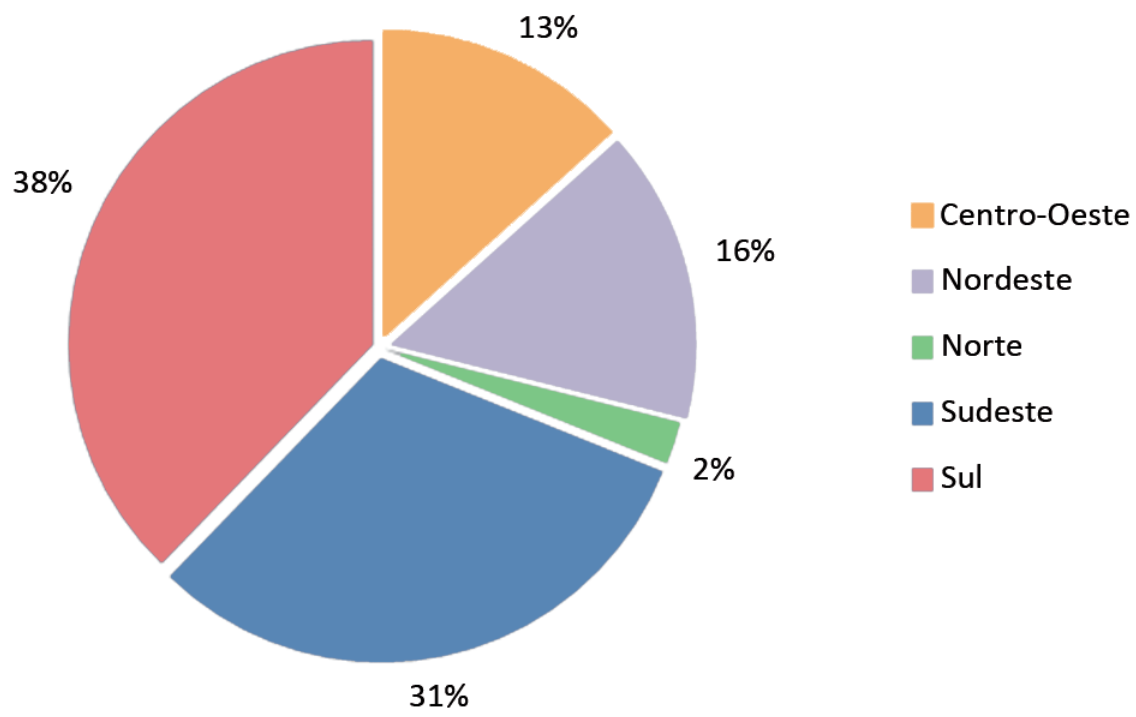

Fonte: CNPq (2014), elaboração própria.

Quanto à evolução histórica dos núcleos de pesquisa sobre a América Latina, observa-se que, desde 2010, tem ocorrido um crescimento expressivo do número de grupos (ver Gráficos 2 e 3). Até 2010, surgia de um a dois núcleos por ano. A partir de então, foram nove grupos por ano em 2010 e 2011, sete em 2012 e dois em 2013.

Um fato que incidiu sobre o crescimento expressivo do número de grupos foi a criação da Universidade Federal da Integração Latino-Americana (Unila), em Foz do Iguaçu (PR). A Unila iniciou suas atividades em 2010 e conta com discentes e docentes de vários países latino-americanos. Em 2011, surgiram os grupos América Latina: Integração e Desenvolvimento e Região Andina em Foco. Em 2012, foi a vez do grupo Pós-Colonialidade e Integração Latino-Americana. 
Gráfico 2 - Evolução do número de grupos de pesquisa

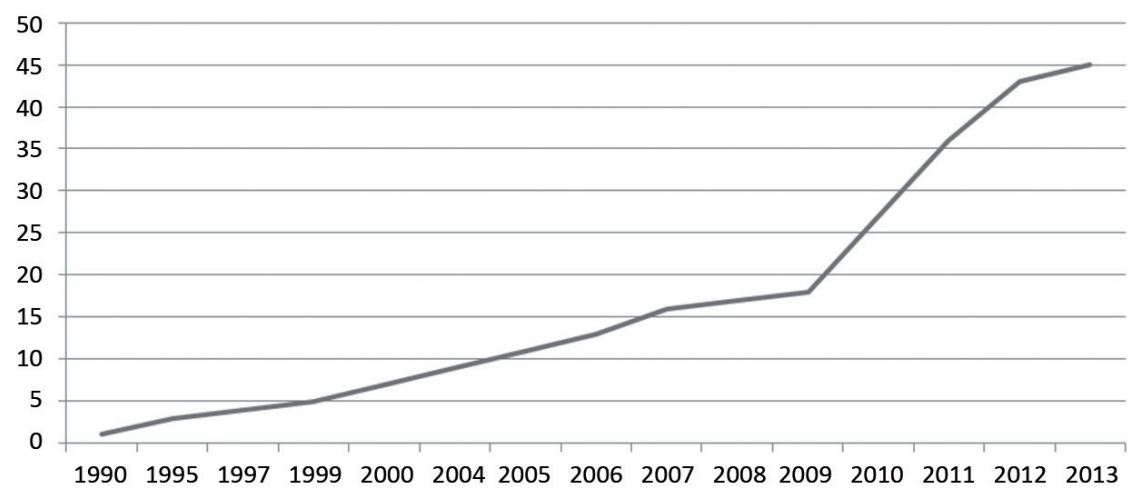

Fonte: CNPq (2014), elaboração própria.

O Gráfico 3 apresenta a evolução do número de grupos por ano, considerando todos os anos em que houve ao menos um núcleo criado. Se o crescimento foi expressivo desde 2010, não foi criado um único núcleo de pesquisa da área de ciência política e relações internacionais com tema relacionado com a América Latina entre 1991 e 1994, em 1996, em 1998 e entre 2001 e 2003.

Gráfico 3 - Evolução dos grupos de pesquisa criados por ano

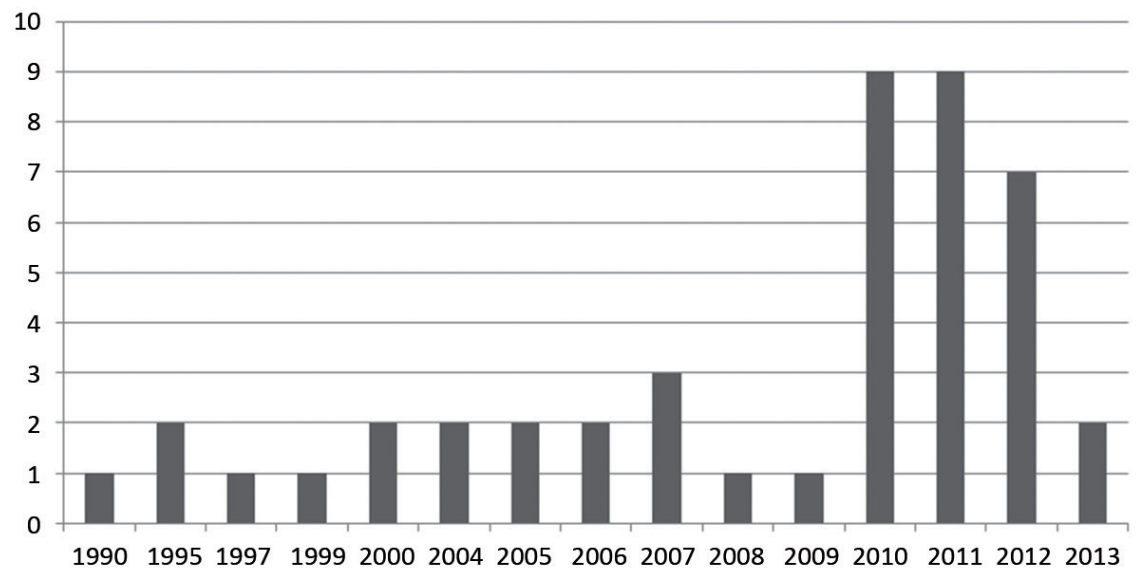

Fonte: CNPq (2014), elaboração própria. 
O primeiro grupo de ciência política e relações internacionais cadastrado no $\mathrm{CNPq}$ que trabalha com tema relacionado com a América Latina é o Núcleo de Estudos da Violência, da Universidade de São Paulo (USP). O grupo foi criado em 1990 e, entre suas dezoito linhas de pesquisa, abriga a de "Mecanismos extrajudiciais de reparações às vítimas de violações aos direitos humanos: as experiências latino-americanas". Outro núcleo surgido nos anos 1990 que merece destaque é o Partidos, Comportamento Eleitoral e Estudos Políticos Comparados, criado em 1995 na Universidade Federal do Rio Grande do Sul (UFRGS). O grupo conta com duas linhas de pesquisas sobre a América Latina, a de "Instituições políticas comparadas" e a de "Partidos e comportamento eleitoral no Cone Sul da América Latina". Tanto a USP como a UFRGS têm, cada uma, três núcleos da área de ciência política e relações internacionais que trabalham com temas ligados à América Latina.

Em relação às linhas de pesquisa dos grupos, há um predomínio do tema da integração regional, o que reflete a expansão dos cursos de relações internacionais no Brasil. Como, para CNPq e Capes, a ciência política e as relações internacionais são uma única área, tal expansão também se reflete no crescimento dos núcleos de pesquisa.

O conjunto dos dados mostra que o interesse pela América Latina na ciência política brasileira tem aumentado no que se refere aos temas dos núcleos de pesquisa cadastrados no CNPq. Os grupos que estudam temas relacionados com a América Latina são cada vez mais numerosos ${ }^{1}$ e estão espalhados pelas regiões brasileiras, apesar da referida concentração no Sul e no Sudeste, onde tradicionalmente estão os principais centros de pesquisa da ciência política nacional.

\section{A América Latina nos programas de pós-graduação em ciência política}

No Brasil, há 36 programas de pós-graduação em ciência política e relações internacionais recomendados e reconhecidos pela Capes, divididos entre os que têm só mestrado e os que também oferecem doutorado. Uma terceira modalidade é a de mestrado profissional² ${ }^{2}$ sobretudo na área de políticas públicas.

1 É certo que o número de grupos cresceria com o passar dos anos sob o critério de número acumulado de núcleos, mas poderia haver um ritmo lento ou até uma estagnação, já que, pelas regras do CNPq, os grupos podem ser extintos por falta de atividade.

2 Mestrado profissional é a designação do curso que enfatiza estudos e técnicas diretamente relacionados à obtenção de um nível alto de qualificação profissional. Essa ênfase é a única diferença em relação ao mestrado acadêmico (Capes, 2014). 
Segundo a Capes (2011):

Entre 2005 e 2011, a área de ciência política e relações internacionais consolidou tendência em duas direções: (a) uma expansão significativa no número de mestrados e doutorados; e (b) um reforço na qualificação dos programas, medida pelo aumento na produção científica internacional e de qualidade, nas teses de doutorado e, especialmente, na proporção de programas de excelência em relação ao conjunto da área. Neste período, registrou-se um crescimento de 138\% no número de programas com mestrado, variação ainda mais significativa quando se leva em conta o crescimento de cursos de doutorado na área (150\%). Estes números situam-se bem acima da expansão registrada para o conjunto do sistema de pós-graduação no país, que foi de, respectivamente, 59,7\% (M) e 63,9\% (M/D) (Capes, 2011, p. 2).

Dos 36 programas, apenas seis têm conceito acima de cinco na avaliação da Capes, sendo quatro com conceito seis e dois com conceito sete, o nível máximo. Os cursos com conceito sete são os da USP e da UFMG, que se configuram, assim, como os centros de excelência da ciência política no Brasil. Quanto à natureza, os programas com mestrado e doutorado prevalecem e correspondem a 47,22\% do total, como mostra a Tabela 1 .

Tabela 1 - Distribuição dos programas de pós-graduação por tipo

\begin{tabular}{c|c|c}
\hline tipo de programa & quantidade & $\%$ \\
\hline mestrado & 13 & 36,11 \\
\hline mestrado/doutorado & 17 & 47,22 \\
\hline mestrado profissional & 6 & 16,66 \\
\hline Total & 36 & 100,00 \\
\hline
\end{tabular}

Fonte: Capes (2014), elaboração própria.

Ainda que seja uma única área de avaliação, os dados da Capes permitem que os programas de pós-graduação em ciência política sejam separados dos que são de relações internacionais, o que não ocorre com os grupos de pesquisa. Para Cruz e Mendonça (2010), a existência das áreas de ciência política e relações internacionais é uma consequência da "saudável lógica da divisão social do trabalho". No Brasil, as duas áreas são uma única para as instâncias regulatórias da pesquisa e da pós-graduação, o que, para os autores, não é uma solução. 
O problema não se resolve de maneira tão simples. Cada domínio do saber tem a sua história, o seu modo próprio de conceber a realidade (ainda que esse seja frequentemente objeto de intensa disputa), suas formas características de abordar os temas de estudo e de interagir com os domínios que lhe são afins. Com raízes plantadas na história diplomática, no direito público internacional e no ramo correspondente da economia, com o passar do tempo, as relações internacionais adquirem identidade própria, e nem sempre seus praticantes se reconhecem como cientistas políticos (Cruz e Mendonça, 2010, p. 298).

Com a possibilidade de identificar os programas de cada área, a opção aqui foi limitar a avaliação do interesse pela América Latina aos programas em ciência política, o que não significa uma tomada de posição sobre a delimitação do campo no Brasil. Dessa forma, os resultados se tornam mais acurados, já que o interesse por cenários externos, que é justamente o objeto de análise deste trabalho, é intrínseco à área de relações internacionais. A Tabela 2 apresenta os cursos considerados.

Tabela 2 - Programas de pós-graduação em ciência política no Brasil

\begin{tabular}{c|c|c|c|c|c|c|c}
\hline curso & instituição & UF & região & tipo & nota & mestrado & doutorado \\
\hline Ciência política & UnB & DF & Centro-0este & M/D & 5 & 1984 & 2008 \\
\hline Ciência política & UFMG & MG & Sudeste & M/D & 7 & 1969 & 2006 \\
\hline Ciência política & UFF & RJ & Sudeste & M/D & 4 & 1994 & 2006 \\
\hline Ciência política & UFRGS & RS & Sul & M/D & 5 & 1973 & 1996 \\
\hline Ciência política & USP & SP & Sudeste & M/D & 7 & 1974 & 1974 \\
\hline Ciência política & Unicamp & SP & Sudeste & M/D & 5 & 1974 & 2006 \\
\hline Ciência política & UFG & GO & Centro-0este & M & 4 & 2012 & - \\
\hline Ciência política & UFPA & PA & Norte & M & 3 & 2008 & - \\
\hline Ciência política & UFPE & PE & Nordeste & M/D & 6 & 1982 & 2002 \\
\hline Ciência política & UFPI & PI & Nordeste & M & 3 & 2008 & - \\
\hline Ciência política & UFPR & PR & Sul & M/D & 4 & 2009 & 2014 \\
\hline Ciência política & Uerj & RJ & Sudeste & M/D & 6 & 2010 & 2010 \\
\hline Ciência política & UFPel & RS & Sul & M & 3 & 2011 & - \\
\hline Ciência política & Ufscar & SP & Sudeste & M/D & 4 & 2008 & 2008 \\
\hline
\end{tabular}

Fonte: Capes (2014), elaboração própria. 
Dos catorze programas, o único com uma linha de pesquisa explicitamente sobre a América Latina é o da Universidade Federal de Goiás (UFG), que, entre suas quatro linhas, conta com a de "América Latina e política comparada". O interesse pela região não se limita ao curso da UFG. Em quase todos os programas de pós-graduação em ciência política já foram defendidos trabalhos sobre a América Latina. A Tabela 3 apresenta o número de dissertações e teses defendidas nesses programas entre 1998 e 2012. Para cada item considerado (dissertação, tese e total), a primeira coluna traz a quantidade de trabalhos defendidos, a segunda, os que foram sobre a América Latina, e a terceira, a proporção que representam.

Tabela 3 - Dissertações e teses sobre a América Latina

\begin{tabular}{c|c|c|c|c|c|c|c|c|c}
\hline \multirow{2}{*}{ instituição } & \multicolumn{3}{|c|}{ dissertação } & \multicolumn{3}{c|}{ tese } & \multicolumn{3}{c}{ total } \\
\cline { 2 - 11 } & I & $\|$ & $\%$ & I & II & $\%$ & I & I & $\%$ \\
\hline UnB & 190 & 7 & $3,7 \%$ & 3 & 1 & $33,3 \%$ & 193 & 8 & $4,1 \%$ \\
\hline UFMG & 146 & 5 & $3,4 \%$ & 29 & 4 & $13,8 \%$ & 175 & 9 & $5,1 \%$ \\
\hline UFF & 136 & 3 & $2,2 \%$ & 14 & 2 & $14,3 \%$ & 150 & 5 & $3,3 \%$ \\
\hline UFRGS & 158 & 13 & $8,2 \%$ & 79 & 9 & $11,4 \%$ & 237 & 22 & $9,3 \%$ \\
\hline USP & 248 & 21 & $8,5 \%$ & 192 & 20 & $10,4 \%$ & 440 & 41 & $9,3 \%$ \\
\hline Unicamp & 163 & 12 & $7,4 \%$ & 30 & 1 & $3,3 \%$ & 193 & 13 & $6,7 \%$ \\
\hline UFG & 0 & 0 & $0,0 \%$ & 0 & 0 & $0,0 \%$ & 0 & 0 & $0,0 \%$ \\
\hline UFPA & 31 & 0 & $0,0 \%$ & 0 & 0 & $0,0 \%$ & 31 & 0 & $0,0 \%$ \\
\hline UFPE & 164 & 16 & $9,8 \%$ & 27 & 2 & $7,4 \%$ & 191 & 18 & $9,4 \%$ \\
\hline UFPI & 20 & 1 & $5,0 \%$ & 0 & 0 & $0,0 \%$ & 20 & 1 & $5,0 \%$ \\
\hline UFPR & 29 & 3 & $10,3 \%$ & 0 & 0 & $0,0 \%$ & 29 & 3 & $10,3 \%$ \\
\hline Uerj & 25 & 4 & $16,0 \%$ & 31 & 7 & $22,6 \%$ & 56 & 11 & $19,6 \%$ \\
\hline UFPel & 1 & 0 & $0,0 \%$ & 0 & 0 & $0,0 \%$ & 1 & 0 & $0,0 \%$ \\
\hline Ufscar & 48 & 2 & $4,2 \%$ & 10 & 1 & $10,0 \%$ & 58 & 3 & $5,2 \%$ \\
\hline total & 1359 & 87 & $6,4 \%$ & 415 & 47 & $11,33 \%$ & 1774 & 134 & $7,55 \%$ \\
\hline
\end{tabular}

Fonte: Capes (2014), elaboração própria.

O programa com o maior número de trabalhos defendidos de 1998 a 2012 foi o da USP, com 440, sendo 248 dissertações e 192 teses, seguido pelo da UFRGS, com 237, sendo 158 dissertações e 79 teses. Dos 1774 trabalhos defendidos no período, 134 (7,55\% do total) enfocaram a América Latina, sendo 87 dissertações $(6,40 \%)$ e 47 teses $(11,33 \%)$. 
O programa que apresenta a maior proporção de trabalhos sobre a região é o da Universidade do Estado do Rio de Janeiro (Uerj), com 19,60\%, seguido pelo da Universidade Federal do Paraná (UFPR), com 10,30\%. No caso das dissertações, os cursos da Uerj e da UFPR aparecem nas mesmas posições, com 16,0\% e 10,30\%, respectivamente. Quanto às teses, as maiores proporções são dos programas da Universidade de Brasília (UnB), com 33,30\%, e da Uerj, com 22,60\%. A UnB, porém, só teve três teses defendidas até 2012, o último ano para o qual a Capes disponibilizava dados no momento da pesquisa, sendo que uma foi sobre a América Latina. De forma geral, então, é no curso da Uerj que a região desperta mais interesse.

Para se avaliar melhor o nível de interesse pela América Latina, é necessário verificar a evolução ao longo do período considerado. A Tabela 4 apresenta as proporções de trabalhos sobre a região por ano.

Tabela 4 - Evolução das dissertações e teses sobre a América Latina

\begin{tabular}{c|c|c|c|c|c|c|c|c|c}
\hline \multirow{2}{*}{ anos } & \multicolumn{3}{|c|}{ dissertação } & \multicolumn{3}{c|}{ rese } & \multicolumn{3}{c}{ Total } \\
\cline { 2 - 11 } & I & II & $\%$ & I & II & $\%$ & I & I & $\%$ \\
\hline 1998 & 57 & 3 & $5,3 \%$ & 18 & 1 & $5,6 \%$ & 75 & 4 & $5,3 \%$ \\
\hline 1999 & 65 & 2 & $3,1 \%$ & 8 & 1 & $12,5 \%$ & 73 & 3 & $4,1 \%$ \\
\hline 2000 & 63 & 1 & $1,6 \%$ & 15 & 3 & $20,0 \%$ & 78 & 4 & $5,1 \%$ \\
\hline 2001 & 74 & 2 & $2,7 \%$ & 6 & 1 & $16,7 \%$ & 80 & 3 & $3,8 \%$ \\
\hline 2002 & 63 & 1 & $1,6 \%$ & 11 & 2 & $18,2 \%$ & 74 & 3 & $4,1 \%$ \\
\hline 2003 & 83 & 2 & $2,4 \%$ & 20 & 0 & $0,0 \%$ & 103 & 2 & $1,9 \%$ \\
\hline 2004 & 84 & 6 & $7,1 \%$ & 14 & 0 & $0,0 \%$ & 98 & 6 & $6,1 \%$ \\
\hline 2005 & 94 & 8 & $8,5 \%$ & 25 & 4 & $16,0 \%$ & 119 & 12 & $10,1 \%$ \\
\hline 2006 & 102 & 4 & $3,9 \%$ & 24 & 3 & $12,5 \%$ & 126 & 7 & $5,6 \%$ \\
\hline 2007 & 70 & 9 & $12,9 \%$ & 27 & 0 & $0,0 \%$ & 97 & 9 & $9,3 \%$ \\
\hline 2008 & 78 & 6 & $7,7 \%$ & 27 & 1 & $3,7 \%$ & 105 & 7 & $6,7 \%$ \\
\hline 2009 & 131 & 11 & $8,4 \%$ & 50 & 5 & $10,0 \%$ & 181 & 16 & $8,8 \%$ \\
\hline 2010 & 136 & 12 & $8,8 \%$ & 53 & 9 & $17,0 \%$ & 189 & 21 & $11,1 \%$ \\
\hline 2011 & 149 & 14 & $9,4 \%$ & 61 & 6 & $9,8 \%$ & 210 & 20 & $9,5 \%$ \\
\hline 2012 & 139 & 8 & $5,8 \%$ & 69 & 13 & $18,8 \%$ & 208 & 21 & $10,1 \%$ \\
\hline Total & 1359 & 87 & $6,40 \%$ & 415 & 47 & $11,33 \%$ & 1774 & 134 & $7,55 \%$ \\
\hline
\end{tabular}

Fonte: Capes (2014), elaboração própria. 
De 1998 a 2012, a proporção de trabalhos sobre a América Latina passou de $5,30 \%$ para $10,10 \%$, chegando a $11,10 \%$ em 2010 . No caso das teses, o crescimento foi até mais significativo, de $5,60 \%$ para $18,80 \%$. O único ano com um percentual superior foi 2000 , com $20 \%$. Por outro lado, houve três teses sobre a região naquele ano, contra treze em 2012. Nas dissertações, a proporção se manteve quase igual e foi de 5,30\% para 5,80\%, mas os anos imediatamente anteriores a 2012 apresentaram percentuais maiores, com destaque para os 12,90\% de 2007.

Em números absolutos, o que se nota inicialmente é o aumento da produção geral de dissertações e teses na ciência política brasileira. Os anos que tiveram as maiores quantidades de trabalhos defendidos foram 2011, com 210, 2012, com 208, e 2010, com 189. Algo similar se passou com os trabalhos sobre a América Latina, pois 2010 e 2012 foram os anos com o maior número, 21 em cada. No início do período considerado, foram quatro. O Gráfico 4 apresenta a evolução das proporções de dissertações, teses e trabalhos sobre a América Latina defendidos nos programas de pós-graduação em ciência política no Brasil entre 1998 e 2012.

Gráfico 4 - Evolução das proporções de dissertações e teses sobre a América Latina

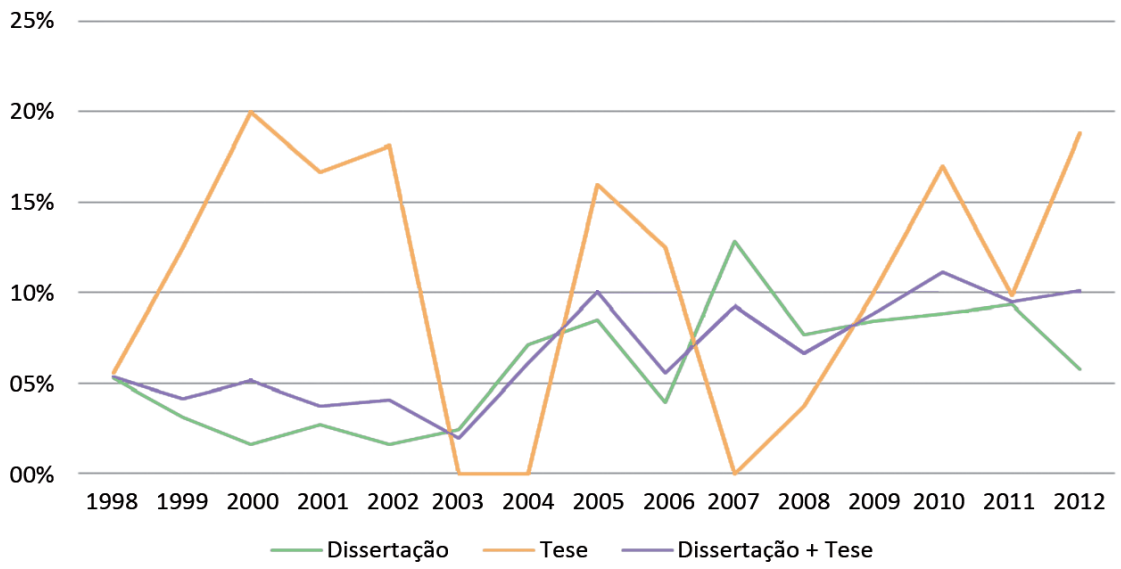

Fonte: Capes (2014), elaboração própria.

Se o aumento da proporção de teses sobre a América Latina é claro ao longo do período, a oscilação também chama a atenção. Em 2003, 2004 e 2007, nenhuma tese sobre a região foi defendida. Essa oscilação desaparece 
no Gráfico 5, que apresenta a evolução dos números absolutos de trabalhos sobre a América Latina.

Gráfico 5 - Evolução do número de dissertações e teses sobre a América Latina

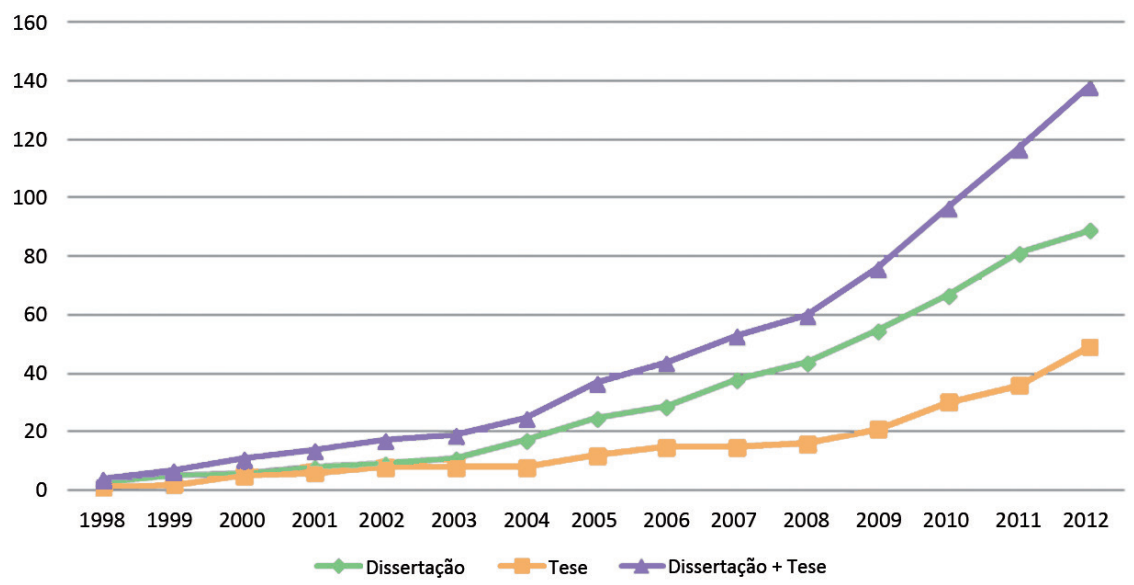

Fonte: Capes (2014), elaboração própria.

O gráfico demonstra o crescimento dos trabalhos sobre a América Latina nos programas de pós-graduação em ciência política no Brasil, o que coincide com a expansão da produção geral de dissertações e teses nesses cursos.

\section{A América Latina em periódicos que publicam temas de ciência política}

Os periódicos científicos são avaliados no Brasil por meio do sistema Qualis, que os classifica em estratos por área de avaliação e utiliza as informações sobre a produção do corpo docente dos programas de pós-graduação registradas no aplicativo Coleta de Dados. Como resultado, a Capes disponibiliza a classificação das revistas, atualizada regularmente. São as áreas de avaliação da Capes que classificam os periódicos em que é publicada a produção dos docentes vinculados aos programas de pós-graduação sob a alçada de cada área. Os estratos vão de A1, o mais alto, passando por A2, B1, B2, B3, B4 e $\mathrm{B} 5$ até $\mathrm{C}$, o mais baixo. Uma mesma revista pode ser classificada por mais de uma área de avaliação e receber conceitos distintos. As classificações, então, 
são um instrumento específico do processo de avaliação de cada área e não definem a qualidade de um periódico de forma geral.

A Tabela 5 mostra algumas revistas brasileiras classificadas nos estratos mais altos da área de avaliação de ciência política e relações internacionais.

\section{Tabela 5 - Periódicos dos principais estratos da área de ciência política e relações internacionais}

\begin{tabular}{c|c|c}
\hline ISSN-ISBN & Periódico & Qualis \\
\hline $0011-5258$ & Dados - Revista de Ciências Sociais & $\mathrm{A} 1$ \\
\hline $0104-6276$ & Opinião Pública & $\mathrm{A} 1$ \\
\hline $0102-6909$ & Revista Brasileira de Ciências Sociais & $\mathrm{A} 1$ \\
\hline $1981-3821$ & Brazilian Political Science Review & $\mathrm{A} 2$ \\
\hline $0102-8529$ & Contexto Internacional & $\mathrm{A} 2$ \\
\hline $0102-6445$ & Lua Nova & $\mathrm{A} 2$ \\
\hline $1678-9873$ & Revista de Sociologia e Política & $\mathrm{A} 2$ \\
\hline $0034-7329$ & Revista Brasileira de Política Internacional & $\mathrm{A} 2$ \\
\hline $0101-3459$ & Perspectivas: Revista de Ciências Sociais & $\mathrm{B} 1$ \\
\hline $1981-0865$ & Sociedade e Estado & $\mathrm{B} 1$ \\
\hline $0103-2070$ & Tempo Social & $\mathrm{B} 1$ \\
\hline $1518-4471$ & Teoria \& Sociedade & $\mathrm{B} 1$ \\
\hline $2178-4884$ & Revista Brasileira de Ciência Política & $\mathrm{B} 1$ \\
\hline
\end{tabular}

Fonte: SciELO (2014), elaboração própria.

Os periódicos selecionados para verificar a produção da ciência política brasileira sobre a América Latina são a Dados - Revista de Ciências Sociais, a Opinião Pública, a Revista Brasileira de Ciências Sociais, o Brazilian Political Science Review, a Lua Nova, a Revista de Sociologia e Política, a Revista Brasileira de Ciência Política, a Sociedade e Estado e a Tempo Social.

As seis primeiras são as mesmas usadas por Soares, Souza e Moura (2011). As outras três foram selecionadas porque são da classificação B1 e estão disponíveis no $\mathrm{SciELO}^{3}$, com base na avaliação de que um levantamento restrito aos estratos A seria menos representativo da ciência política brasileira.

3 É uma biblioteca eletrônica com uma coleção selecionada de periódicos científicos brasileiros, como resultado de um projeto financiado pela FAPESP (Fundação de Amparo à Pesquisa do Estado de São Paulo) e, desde 2002, pelo CNPq. O objetivo é desenvolver uma metodologia comum para preparação, armazenamento, disseminação e avaliação da produção científica em formato eletrônico (SciELO, 2014). 
Para cada periódico, foram avaliados os artigos de todas as edições que estavam disponíveis no SciELO no momento da pesquisa ${ }^{4}$. Os artigos publicados pelas nove revistas selecionadas não são necessariamente de autores que têm vínculo direto com a ciência política brasileira, mas foram encarados como produção da disciplina no país pelo fato de serem classificados nos principais estratos de avaliação da área de ciência política e relações internacionais. Do total de artigos publicados por essas revistas no período estudado avaliou-se quais tratam de temas relacionados com a América Latina. Para refinar a análise da autoria, foram identificados os autores que publicaram mais de um artigo sobre a região e verificadas suas informações pessoais, como país de origem e vínculo institucional.

Considerando as três revistas de cada estrato (A1, A2 e B1) em conjunto, a proporção de artigos sobre a América Latina em relação ao total varia pouco entre uma classificação e outra, como mostra o Gráfico 6. O estrato A2 é o que apresenta a maior proporção.

Gráfico 6 - Distribuição de artigos sobre a América Latina por estrato Qualis

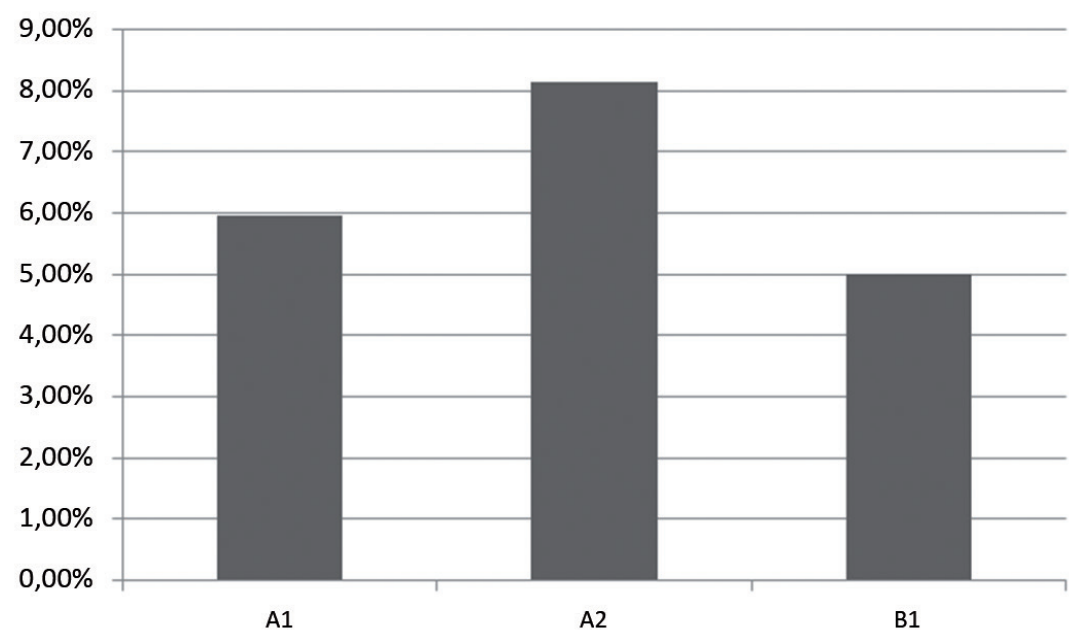

Fonte: elaboração própria.

4 Como a Revista Brasileira de Ciência Política é a mais recente das nove selecionadas e tem uma coleção pequena disponível no SciELO, que começa pelas edições de 2011, também foram considerados os números anteriores ao primeiro disponível na plataforma. 
Avaliando por revista, a disparidade aumenta (ver Gráfico 7). O periódico com a maior proporção de trabalhos sobre a América Latina é a Opinião Pública, com 17,3\%, seguida pelo Brazilian Political Science Review, com 10\%, e pela Revista de Sociologia e Política, com 9,88\%. As menores proporções são da Revista Brasileira de Ciências Sociais, com 1,59\%, da Sociedade e Estado, com 3,18\%, e da Dados, com 5,47\%. No conjunto dos nove periódicos selecionados, os artigos sobre a América Latina representaram 6,6\% do total.

Gráfico 7 - Distribuição de artigos sobre a América Latina por periódico

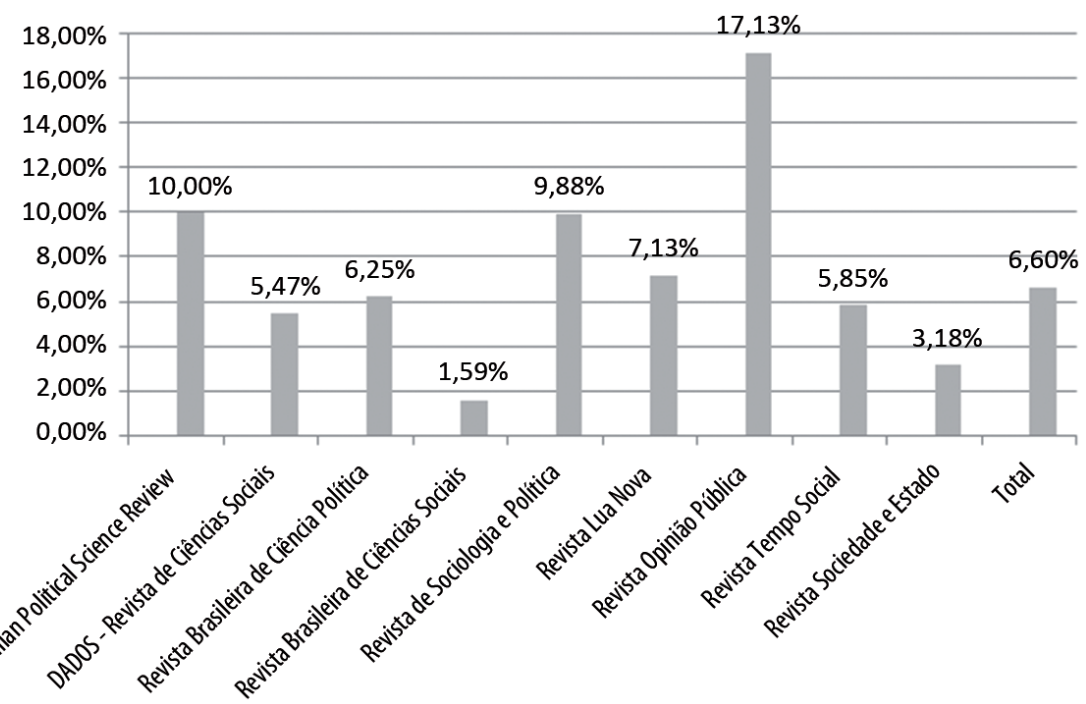

Fonte: elaboração própria.

Para se ter uma dimensão do que essas proporções representam, é necessário comparar a produção sobre a América Latina com o que se publica nos periódicos selecionados sobre outras regiões e os Estados Unidos. Em oito das nove revistas, a América Latina foi tema de mais artigos do que os Estados Unidos, a Europa ou outras regiões, como mostra a Tabela 6. A exceção foi a Revista Brasileira de Ciências Sociais, em que a Europa foi tema de mais trabalhos do que a América Latina. No conjunto das nove revistas, foram 220 artigos sobre a América Latina, 86 sobre a Europa, 27 sobre os Estados Unidos e 25 sobre outras regiões. 
Por outro lado, a proporção de artigos sobre a América Latina no conjunto de periódicos selecionados, de 6,6\%, fica abaixo da média que Carpiuc (2014) apurou para três países latino-americanos - a Argentina, o próprio Brasil e o México - no período de 2000 a 2012. Em uma amostra com sete revistas da área de ciência política (duas argentinas, duas brasileiras e três mexicanas), a autora encontrou $21,3 \%$ de artigos sobre outro país ou um grupo de países da região.

Tabela 6 - Publicações sobre América Latina, Estados Unidos, Europa e outras regiões

\begin{tabular}{c|c|c|c|c|c}
\hline periódico & artigos & América Latina & $\begin{array}{c}\text { Estados } \\
\text { Unidos }\end{array}$ & Europa & $\begin{array}{c}\text { outras } \\
\text { regiões }\end{array}$ \\
\hline Brazilian Political Science Review & 70 & 7 & 3 & 3 & 1 \\
\hline Dados-Revista de Ciências Sociais & 439 & 24 & 2 & 14 & 5 \\
\hline Revista Brasileira de Ciência Política & 128 & 8 & 1 & 4 & 2 \\
\hline Revista Brasileira de Ciências Sociais & 504 & 8 & 3 & 16 & 5 \\
\hline Revista de Sociologia e Política & 425 & 42 & 6 & 6 & 4 \\
\hline Lua Nova & 856 & 61 & 9 & 20 & 1 \\
\hline Opinião Pública & 216 & 37 & 2 & 2 & 0 \\
\hline Tempo Social & 410 & 24 & 1 & 17 & 4 \\
\hline Sociedade e Estado & 283 & 9 & 0 & 4 & 3 \\
\hline Total & 3331 & 220 & 27 & 86 & 25 \\
\hline
\end{tabular}

Fonte: elaboração própria.

No período considerado, que vai de 1984 a 2013 por causa do ano inicial das coleções de cada revista disponíveis no SciELO, houve um aumento significativo no número de artigos publicados sobre a América Latina por ano (ver Gráfico 8). Só um dos periódicos selecionados, porém, tem uma coleção disponível no SciELO que cobre o intervalo de 1984 a 1995. Avaliando o período para o qual mais revistas estão com as edições disponíveis, a quantidade de trabalhos seguiu crescendo. Os anos que tiveram maior número de artigos foram 2009, com 25, e 2012, com 24. 
Gráfico 8 - Evolução do número de artigos sobre a América Latina

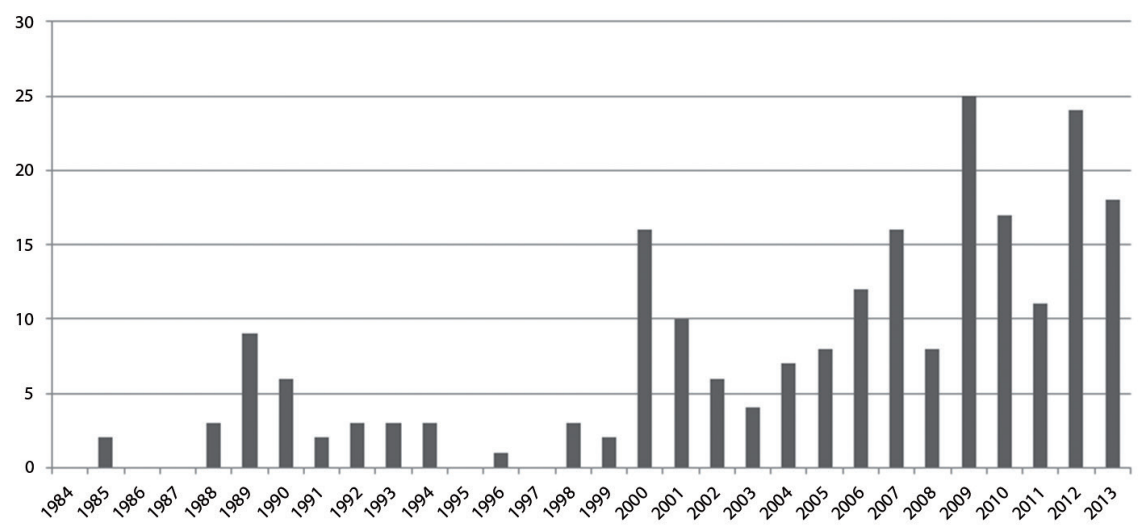

Fonte: elaboração própria.

Em termos proporcionais, a produção mais representativa foi a de 1990, para quando os seis trabalhos publicados sobre a América Latina significaram 30,0\% do total (ver Gráfico 9). Como já foi explicado, porém, esse percentual se refere a um único periódico. Desde que o universo de artigos superou uma centena, a proporção de trabalhos sobre a região passou de 2,9\%, em 1998, para 8,3\%, em 2013, chegando a representar 11,3\% em 2009.

Gráfico 9 - Evolução da proporção de artigos sobre a América Latina

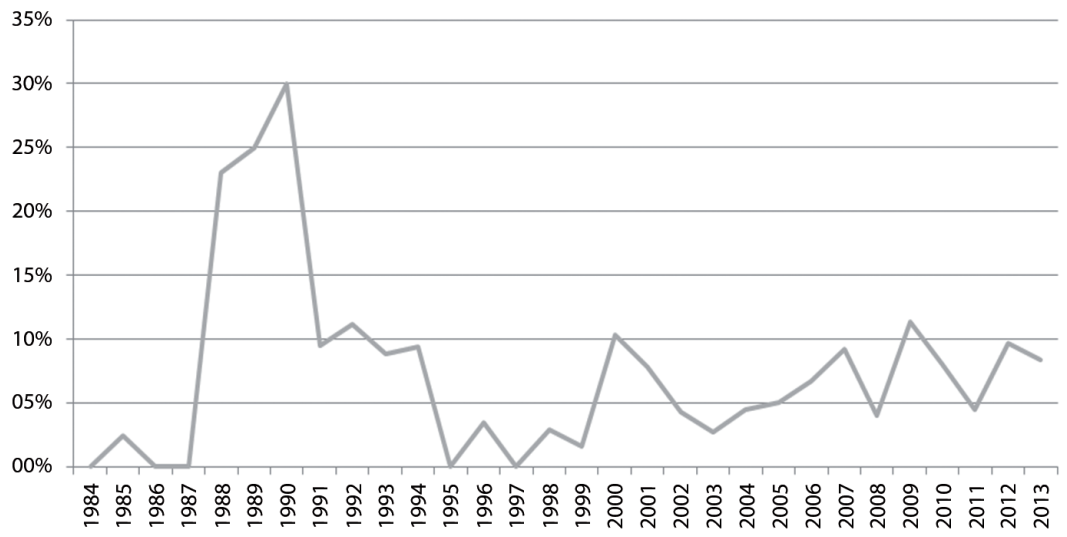

Fonte: elaboração própria. 
O interesse na América Latina precisa ser relativizado pela análise dos países de origem e atuação dos autores que publicaram mais de um artigo sobre a região nas revistas selecionadas. Dos 23 que integram esse grupo, apenas nove são brasileiros, sendo que um não atua no país. Há ainda três que são estrangeiros e trabalham no Brasil. Dos onze que atuam no país, incluindo brasileiros e estrangeiros, um não pode ser considerado profissional da ciência política. Em termos de nacionalidade, os maiores contingentes são os de Argentina e Brasil, com nove autores cada. Pelo critério do país de atuação, o Brasil se distancia da Argentina, com onze contra cinco. O grupo dos que publicaram mais de um trabalho tem ainda dois chilenos, um alemão, uma mexicana e um venezuelano. A maioria dos autores com mais de um artigo sobre a América Latina nos periódicos selecionados, portanto, é de origem estrangeira.

\section{Conclusões}

Os dados apresentados até aqui mostraram que, nos períodos avaliados em cada item, houve uma expansão dos grupos de pesquisa da área de ciência política e relações internacionais que trabalham com temas relacionados com a América Latina, dos trabalhos sobre a região defendidos nos programas de pós-graduação em ciência política e dos artigos sobre a América Latina nas revistas selecionadas que publicam temas de ciência política. No caso dos dois últimos itens, a expansão ocorreu tanto em termos absolutos quanto proporcionais.

Com isso, o interesse da ciência política brasileira sobre a América Latina foi maior do que a expectativa inicial. Em comparaçãocom o interesse por outras regiões e pelos Estados Unidos, a América Latina foi tema de mais artigos em oito dos nove periódicos selecionados. Essa comparação com a produção sobre outras regiões fornece um parâmetro comparativo para avaliar o nível de interesse da ciência política brasileira pela América Latina.

Por outro lado, há dados que relativizam o interesse crescente sobre a região, inclusive em termos comparativos. A média de artigos sobre outro país ou um grupo de países da América Latina encontrado por Carpiuc (2014) em revistas de ciência política de três países latino-americanos - a Argentina, o próprio Brasil e o México - foi de 21,3\%, contra 6,6\% no conjunto de periódicos brasileiros considerados. Ademais, só dez dos 23 autores que publicaram mais de um artigo sobre a região nas nove revistas consideradas são profissionais da área de ciência política e relações internacionais no Brasil, incluindo dois que são argentinos e trabalham no país. 
Pode-se concluir então que, apesar da expansão constatada, a pesquisa e a produção sobre a América Latina na ciência política brasileira ainda estão aquém do necessário para um país como o Brasil, que está entre as maiores economias do mundo, busca internacionalizar sua ciência e tem priorizado sua inserção regional.

Uma explicação possível se relaciona com as dificuldades que a ciência política brasileira ainda tem para lidar com um número maior de casos e, assim, incluir outros países latino-americanos nos seus estudos. Uma área fundamental para que mais casos possam ser incluídos, a de política comparada, ainda está pouco estruturada no Brasil, como avaliam Santos e Coutinho (2002), Soares (2005) e González e Baquero (2013). As dificuldades apontadas não se devem ao acesso à informação sobre os demais países latino-americanos, já que muitos dados estão disponíveis na internet.

Os três primeiros autores citados enfatizam outras questões, como os problemas no ensino de comparação e métodos de pesquisa nos programas de pós-graduação em ciência política no Brasil. Santos e Coutinho (2002) analisaram as teses defendidas entre 1985 e 2000 nos programas de ciência política no Brasil e constataram que "nos dez centros de pós-graduação da área da Capes de ciência política, entendendo-se por comparados os estudos que analisam mais de dois países, somente 3\% usavam essa perspectiva e, entre eles, nenhum usava dados quantitativos" (Santos e Coutinho, 2002, p. 28). Segundo os autores, "a área de política comparada, se não é incipiente em termos de volume de trabalhos, artigos e teses que adotam a perspectiva, está incipientemente estruturada" (Santos e Coutinho, 2002, p. 21).

Para Soares (2005), a ciência política brasileira precisa avançar em ensinar, estudar e aplicar métodos, sejam quantitativos ou qualitativos. Entre as deficiências metodológicas que o autor identifica, estão as dificuldades com a comparação, como Santos e Coutinho (2002) já haviam apontado. González e Baquero (2013) mostram que, nos cursos de graduação em ciências sociais analisados, a política comparada é oferecida como uma disciplina optativa. No caso da pós-graduação em ciência política, a disciplina de política comparada estava presente em todos os programas avaliados pelos autores, mas variava a forma de oferecê-la, sendo em separado ou como parte do conteúdo de metodologia e obrigatória ou optativa.

Ampliando o levantamento de González e Baquero no caso da pósgraduação, uma vez que eles se concentram nos cursos com conceitos de 5 a 7, a situação piora. Uma análise dos currículos dos catorze programas 
de pós-graduação em ciência política no Brasil mostra que cinco sequer ofereciam nas grades avaliadas o ensino de política comparada, seja como disciplina específica ou como parte da ementa ou da bibliografia da disciplina obrigatória de metodologia de pesquisa. Na distribuição desses cinco cursos na escala de avaliação da Capes, há dois com conceito 3, um com 4, um com 5 e um com 6. Ou seja, a qualidade do programa não parece ser um indicador para a atenção que dedica ao método comparado.

Sem uma formação consistente em política comparada, a pesquisa e a produção sobre a América Latina no Brasil carecem de apoio metodológico e estímulo. As dificuldades de natureza metodológica para incluir mais casos aos estudos são, então, uma explicação plausível para que a pesquisa e a produção sobre a região na ciência política brasileira ainda não tenham se expandido tanto quanto requereria uma inserção qualificada do país na América Latina.

As conclusões deste trabalho não esgotam, claro, o assunto. Há ao menos duas opções que se abrem para pesquisas futuras: a presença da metodologia comparativa nos grupos de pesquisa, nos programas de pós-graduação e nas revistas da área de ciência política no Brasil; e o papel das agências de fomento à pesquisa na definição das agendas prioritárias na disciplina, já que um pesquisador pode ser incentivado a estudar determinado tema se perceber que sua chance de obter financiamento é maior.

\section{Referências}

ARAÚJO, Ronaldo Ferreira (2009). "Os grupos de pesquisa em ciência, tecnologia e sociedade no Brasil”. Revista Brasileira de Ciência, Tecnologia e Sociedade, v. 1, n. 1, p. 81-97.

CAPES - Coordenação de Aperfeiçoamento de Pessoal de Nível Superior (2014). "Cursos recomendados e reconhecidos" [online]. Disponível em: http://www.capes.gov.br/cursos-recomendados. Acesso em: $1^{\circ}$ fev. 2014. (2011). "Balanços e perspectivas da área: ciência política e relações internacionais" [online]. Disponível em: http://www.capes.gov.br/component/content/article/44-avaliacao/4661-ciencia-politica-e-relacoes-internacionais. Acesso em: $1^{\circ}$ fev. 2014.

CARPIUC, Cecilia Rocha (2014). “¿Hacia una hegemonía del 'modelo mainstream norteamericano'? Enfoques de la ciencia política en América Latina (2000-2012)". Revista Latino-Americana de Investigación Crítica, v. 1, n. 1, p. 133-60. 
CNPq - Conselho Nacional de Desenvolvimento Científico e Tecnológico (2014). Censo dos grupos de pesquisa [online]. Disponível em: http:// dgp.cnpq.br/censos/anexos/index_anexos.htm. Acesso em: $1^{\circ}$ mai. 2014. CRUZ, Sebastião Carlos Velasco \& MENDONÇA, Filipe (2010). "O campo das relações internacionais no Brasil: situação, desafios, possibilidades", em MARTINS, C. B. \& LESSA, R. (orgs.). Horizontes das ciências sociais no Brasil: ciência política. São Paulo: Anpocs, Instituto Ciência Hoje, Barcarolla, Discurso Editorial.

GONZÁLEZ, Rodrigo Stumpf \& BAQUERO, Marcello (2013). "A política comparada na América Latina: dilemas e desafios no Brasil”. Revista Debates, v. 7, n. 3, p. 111-26.

KEINERT, Fábio Cardoso \& SILVA, Dimitri Pinheiro (2010). "A gênese da ciência política brasileira”. Tempo Social, v. 22, n. 1, p. 79-98.

LAPA, José Roberto do Amaral (1977). “América Latina: o modo de produção do conhecimento histórico". Estudos Cebrap, n. 20, p. 164-71.

NASCIMENTO, Afonso (2008). "A política entre a ciência política e a história política no Brasil: uma análise comparativa dos dois campos científicos”. Revista da Fapese, v. 4, n. 1, p. 15-32.

NOHLEN, Dieter (2006). "Ciencia política en América Latina”, em NOHLEN, D. Diccionario de ciencia política: teorías, métodos, conceptos. Ciudad de México: Editorial Porrúa, El Colegio de Veracruz.

PRADO, Maria Ligia Coelho(2001). “À guisa de introdução: pesquisa sobre história da América Latina no Brasil". Revista Eletrônica da ANPHLAC, n. 1, p. 10-11. QUALIS Capes (2014). Sistema Integrado Capes - WebQualis [online]. Disponível em: http://qualis.capes.gov.br/webqualis/principal.seam. Acesso em: $1^{\circ}$ mai. 2014.

REICHEL, Heloisa Jochims (2001). "A produção bibliográfica sobre história da América no Brasil, nas duas últimas décadas do século XX”. Revista Eletrônica da ANPHLAC, n. 1, p. 7-9.

SANTOS, Maria Helena de Castro \& COUTINHO, Marcelo (2002). "Política comparada: estado das artes e perspectivas no Brasil”. Revista Brasileira de Informação Bibliográfica em Ciências Sociais, n. 54, p. 5-42.

SOARES, Gláucio Ary Dillon; SOUZA, Cíntia Pinheiro Ribeiro de \& MOURA, Tatiana Whately de (2011). "Colaboración en la producción científica en la ciencia política y en la sociología brasileñas”. Estudios Sociológicos, v. 29, n. 87 , p. 881-97. 
SOARES, Gláucio Ary Dillon (2005). “O calcanhar metodológico da ciência política no Brasil”. Sociologia, Problemas e Práticas, n. 48, p. 27-52.

(2004). "O portal de periódicos da Capes: dados e pensamentos". Revista Brasileira de Pós-Graduação, v. 1, n. 1, p. 10-25.

SCIELO (2014). Scientific Electronic Library Online. Disponível em: http:// www.scielo.br. Acesso em: $1^{\circ}$ mai. 2014.

\section{Resumo}

O artigo testa a hipótese de que a ciência política brasileira se interessa pouco pela América Latina, usando as bases de CNPq e Capes sobre grupos de pesquisa e programas de pós-graduação e as edições disponíveis no SciELO de uma seleção de revistas. Todos os itens avaliados - grupos de pesquisa da área que estudam a América Latina, trabalhos sobre a região nos programas de pós-graduação e artigos sobre a América Latina nas revistas selecionadas - têm se expandido nos períodos considerados. Por outro lado, alguns dados relativizam esse achado. Apesar da expansão, a pesquisa e a produção sobre a América Latina na ciência política brasileira ainda estão aquém do necessário para um país que prioriza sua inserção na região. A explicação para isso é que a disciplina tem dificuldades metodológicas para incluir mais casos aos estudos que desenvolve.

Palavras-chave: pesquisa, produção, América Latina, ciência política, Brasil.

\section{Abstract}

The paper tests the hypothesis that the Brazilian Political Science has little interest about Latin America, using the databases of CNPq and Capes about research groups and graduate programs and the editions available on SciELO of selected journals. All evaluated items, such as research groups that study Latin America, works about the region in the graduate programs and papers about Latin America in the selected journals, have expanded in the considered periods. On the other side, some data relativize this finding. Despite the expansion, the research and publication about Latin America in the Brazilian political science still are less than necessary for a country that prioritizes its insertion in the region. The explanation is that the discipline has methodological difficulties to include more cases in the studies.

Keywords: research, publication, Latin America, political science, Brazil.

Recebido em 12 de novembro de 2014.

Aprovado em 15 de setembro de 2015. 